\title{
Spawner-recruit relationships and fish stock carrying capacity in aquatic ecosystems
}

\author{
Brian R. MacKenzie ${ }^{1, *}$, Ransom A. Myers ${ }^{2}$, Keith G. Bowen ${ }^{2}$ \\ ${ }^{1}$ Danish Institute for Fisheries Research, Department of Marine Ecology and Aquaculture, Kavalergården 6, \\ 2920 Charlottenlund, Denmark \\ ${ }^{2}$ Department of Biology, Dalhousie University, Halifax, Nova Scotia B3H 4J1, Canada
}

\begin{abstract}
Few marine ecologists have addressed important questions about the relative productivity and carrying capacity of different ecosystems required to support fish populations. Whereas many researchers have investigated interannual variability in recruitment within a stock, we asked whether relationships between spawner abundance and subsequent recruitment are similar among populations ( $n=3$ to 20 ) of the same species, and among species $(n=14)$. We found that a large and significant amount of the variation $\left(\mathrm{R}^{2}=75\right.$ to $\left.95 \%\right)$ in mean-log recruitment is explained by meanlog spawner biomass when the spawner-recruit relationship is examined among populations of the same species. The slopes of these relationships are close to 1 (i.e. proportional). However, mean recruitment per spawner varies greatly among species (range 3 to 10). Some ecosystems allowed cod Gadus morhua, haddock Melanogrammus aeglefinus and herring Clupea harengus populations to produce an average of ca. 8-fold more recruits per spawner than other ecosystems. Also, the abundance of at least 1 species (cod) is strongly related to habitat size. Reasons for the differences in recruit production per spawner between ecosystems are unclear, but the differences themselves may need to be considered in marine ecosystem management contexts.
\end{abstract}

KEY WORDS: Recruitment variability · Stock-recruitment · Fisheries · Carrying capacity · Ecosystems $\cdot$ Production $\cdot$ Habitat

\section{INTRODUCTION}

Recent meta-analytical and comparative studies of fish population dynamics have shown that different fish stocks and species have common patterns in their life histories and population dynamics. For example, maximum lifetime reproductive rate in marine fish populations is relatively constant both within and between 100s of populations (Myers et al. 1999), and some closely related species (and populations within a species) occupying similar ecosystems respond to key environmental signals in predictable ways (Bakun 1996, Brander 2000). These results became evident only after data and information from several stocks and species were combined and standardized in ways that enabled fair and unbiased comparisons.
One of the most important relationships in fisheries ecology is that between spawner biomass (a proxy for egg production) and recruitment within a given stock. This relationship is typically uncertain because of errors in measurement of both recruitment and spawner biomass (Hilborn \& Walters 1992, Marshall et al. 1998) and because of environmental processes whose impact on young fish survival varies between years (Watanabe et al. 1995, Bakun 1996, JarreTeichmann et al. 2000). The relative importance of these sources of uncertainty is unknown. Nevertheless, experience has shown that when fish stocks are reduced to sufficiently low levels, they produce fewer recruits (Myers \& Barrowman 1996).

In this report we consider the recruitment-spawner biomass relationship and compare variability within 
and among stocks and among species using annual data. We evaluate whether variability at any of these organizational levels is functionally related to spawner biomass. We chose to investigate recruitment variability at these levels because studies of the relative importance of spawner biomass and other factors that might affect recruitment, particularly at the among-stock and among-species levels, have received very little attention among fisheries biologists and oceanographers. As a result, some major comparative questions in marine ecology and fisheries population dynamics remain unclear. For example, do some areas of the sea produce more new fish of a given species than other regions after allowing for differences in spawner biomass, and is the mean recruitment per spawner biomass similar for different species throughout their ranges?

We therefore investigate spawner-recruit relationships at multiple levels and the relative roles of spawner biomass and other variables on recruitment at these scales. We hypothesize that the relative influence of spawner biomass on recruitment will be greater among stocks than within stocks, and that recruitment per spawner will be relatively similar among stocks and species. Alternatively, differences in recruitment per spawner among stocks would suggest that some regions are more productive than others, or have a higher carrying capacity, in terms of the production of new recruits per unit spawning biomass. We have recently found evidence that carrying capacity differs significantly among stocks of at least 1 species (cod Gadus morhua) in the north Atlantic, after standardizing the data for differences in spawner biomass and habitat area (Myers et al. 2001). In this paper we will evaluate whether similar differences exist for several other species and stocks using alternative statistical methods. These issues will be evaluated using the extensive data compilation of Myers \& Mertz (1998).

\section{METHODS}

Data sources. Estimates of spawner and recruit abundance were extracted from a comprehensive database containing over 800 time series of fisheries data from all over the world (Myers \& Mertz 1998). The data are derived from virtual population analyses of catch data which have been calibrated with research vessel survey data and/or commercial fleet information. The time period covered by the data series is the last 2 to 4 decades, which corresponds approximately to the period when survey, commercial fleet catch and effort data, and lifehistory data (e.g. mortality rates, maturity ogives) have become more extensive. As a result, the biological responses we report are a consequence of exposure to the combined effects of fishing mortality and environmental conditions experienced during this time period. We further note that most time series contained in the database end in the early to mid-1990s.

Our analyses were confined to species with multiple stocks, and those which were among the most commerically important. We used stocks with at least 10 pairs of spawner recruit data that could be standardized to the same units (biomass in $\mathrm{kg}$; see below for standardization details). If a species had at least 3 stocks it was included. We also used all hakes (members of the genus Merlucius) and 3 species of tuna for comparison. The species, stocks and spawner-recruit data used are available at http://fish.dal.ca./ myers/ papers.html.

The spawner abundance (S) for year $t$ and stock $j, S_{t j}$ is given in numbers of spawners (a proxy for egg production) for Pacific salmon species and biomass of spawners for other species. For salmon species, recruits, $R_{t i}$, is simply the number of returning spawners from that cohort before fishing occurs. For other species recruitment occurs before the age of spawning and differs within and between stocks ( 0 to $5 \mathrm{yr}$ ). Since numbers-at-age decline over time, recruitment estimates from stocks with different recruit ages must be converted to standard units. The recruitment data within each stock were standardized (see equations below) by converting the raw numbers-at-age to the production of new spawners during the stock's expected lifetime in the absence of fishing. Using this conversion, the units of recruitment are the same as the units of spawners; this allows easy comparisons among populations and species.

The standardization follows the calculations by Myers et al. (1996). The standardized recruitment is calculated as the product of the raw recruitment in numbers at age $a, N_{a, t j}$ multiplied by the spawner biomass produced per recruit (SPR) in the absence of fishing, $\mathrm{SPR}_{F=0}$. The standardized recruitment value for a cohort born in year $t$, is estimated as:

$$
R_{t j}=\mathrm{SPR}_{j_{i} F=0} \times N_{a_{i} t j}
$$

where

$$
S P R_{j ; F=0}=\sum_{a=a_{\mathrm{r}}}^{A_{j}} w_{j a} p_{j a} \mathrm{e}^{-\sum_{c=1}^{a-1} M_{j c}}
$$

(Myers et al. 1996), where $w_{j a}=$ weight at age $a_{1} p_{j a}=$ proportion of fish mature at age $a_{1} A_{j}=$ maximum age, $a_{\mathrm{r}}=$ age at recruitment, and $M_{j c}=$ natural mortality at age $c$.

Statistical analyses. All spawner-recruit data were $\log _{10}$-transformed (Hennemuth et al. 1980) to stabilize variances and to normalize the data. We made scatterplots of the standardized recruitment data and spawner 
biomass data to visualize relationships and to assist with the choice of analytical methods. Statistical analyses consisted primarily of regression analyses (dependent and independent variables were log recruitment and log spawner-abundance). We used ordinary leastsquares regression analyses throughout which would lead to a biased estimate of slope parameters towards zero (Fuller 1987). However, the bias is proportional to the ratio of the variance in the estimation error in the independent variable (spawner biomass) to the total observed variance in spawner abundance (Fuller 1987). This bias will be negligible for our analyses among stocks, where the total variation in spawner abundance is many orders of magnitude and larger than variation in the estimation error. For within-stock analyses, the bias is not sufficient to affect our conclusions (Kehler et al. 2002).

We analyzed stock-recruitment data at several levels of aggregation (Fig. 1). We first considered recruitment variability within individual stocks (Fig. 1a). We note that extensive reviews of the variability in recruitment within stocks have been conducted previously by many authors (e.g. Leggett \& Frank 1997, Myers et al. 1997, Iles \& Beverton 1998). These reviews include comparisons of the fits of different formulations of the stock-recruitment relationship (Cushing, Ricker, Beverton-Holt, Shepherd); hence a similar analysis is not repeated here. Instead we apply the Cushing model to all stocks when analysing both within- and among-stock variability. This model is useful for our analyses for 2 reasons: (1) the slope of this model allows us to evaluate the relative role of densitydependence on the stock-recruitment relationship within and among stocks (Cushing 1971); (2) it was a powerful descriptor of the among-stocks relationship between spawner biomass and recruitment (see 'Results' below)

We next considered recruitment variability among stocks (Fig. 1b,c). These analyses compared the fits of log recruitment to log spawner-biomass for 2 levels of data aggregation (interannual data for log recruitment and log spawner-biomass for all stocks within a species, and stock-specific averages of log recruitment and log spawner-biomass). We compared slopes, goodness of fit $\left(\mathrm{R}^{2}\right)$ and a measure of residual variability (standard deviation of the residuals) for both the among-stocks interannual and among-stocks averaged data sets. In addition, we compared geographic differences in residual recruitment variability for 3 species (cod, haddock, herring) which had a large number of stocks. We made this comparison by calculating and ranking residual variation from the among-stocks relationship between mean log spawner-biomass and mean log recruitment for each of these 3 species.

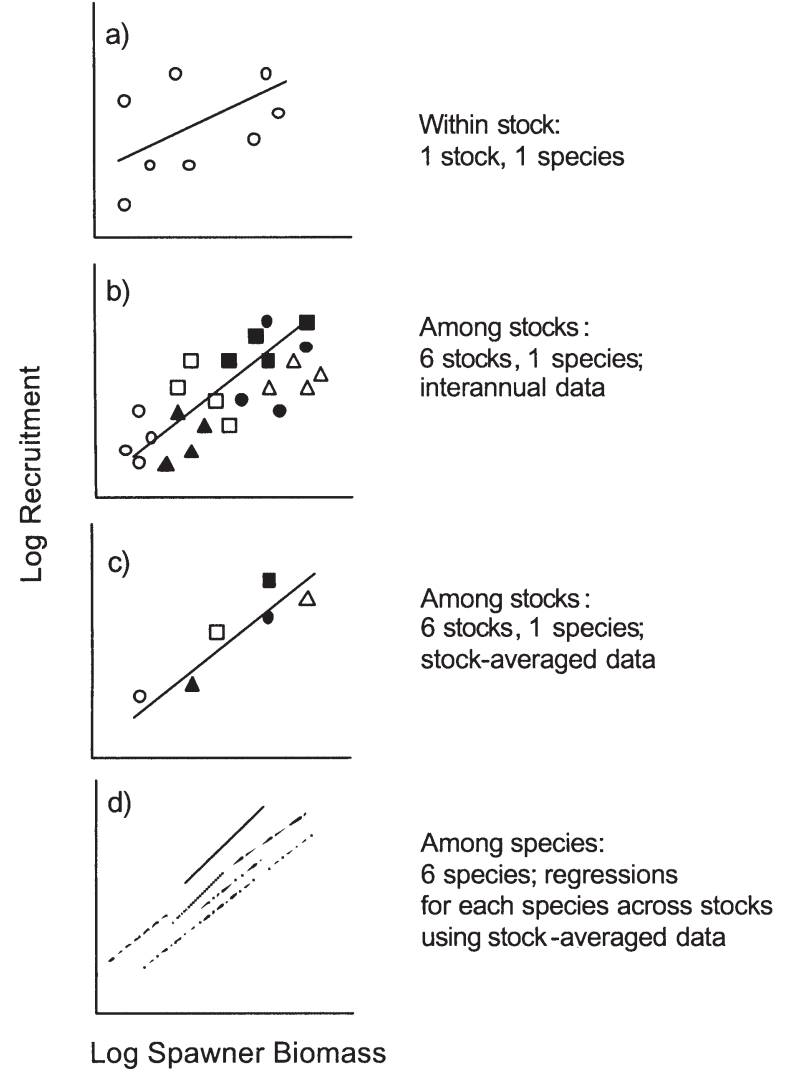

Fig. 1. Schematic representation of different levels of aggregation of spawner biomass and recruitment data used in data analyses. All panels depict logarithmic axes

A final set of analyses considered recruitment variability among species and used stock-specific mean spawner-recruit data (Fig. 1d). In order to compare recruitment variation among species, we needed the mean log recruitment and mean log spawner-biomass for a given stock of a species. This was calculated as follows:

$$
\begin{aligned}
\log R_{j} & =\frac{\sum_{t} \log R_{t j}}{n_{j}} \\
\log S_{j} & =\frac{\sum_{t} \log S_{t j}}{n_{j}}
\end{aligned}
$$

where $n_{j}$ is the number of paired spawner-recruit observations.

A linear regression analysis of the variability in log $R_{j}$ explained by $\log S_{j}$ yields relationships for a species of the form:

$$
\log R_{j}=\gamma \log S_{j}+\log \beta
$$

If $\gamma$ is constrained to be equal to 1 (see 'Results' and Fig. 2f,i), then $\log \beta$ is the mean of $\log R_{j}-\log S_{j}$. 
Habitat area estimates. We investigated the way that habitat size affects recruit and spawner abundance in cod Gadus morhua. Estimates of habitat area (area of sea bottom in each region between 0 and $300 \mathrm{~m}$ ) were obtained from Myers et al. (2001) and were used in exploratory scatterplots and regression analyses.

\section{RESULTS}

\section{Variability within a stock}

We first examined the variability in recruitment among years within stocks (Fig. 1a). As is typical for many species, the within-stock (interannual) variability in re-
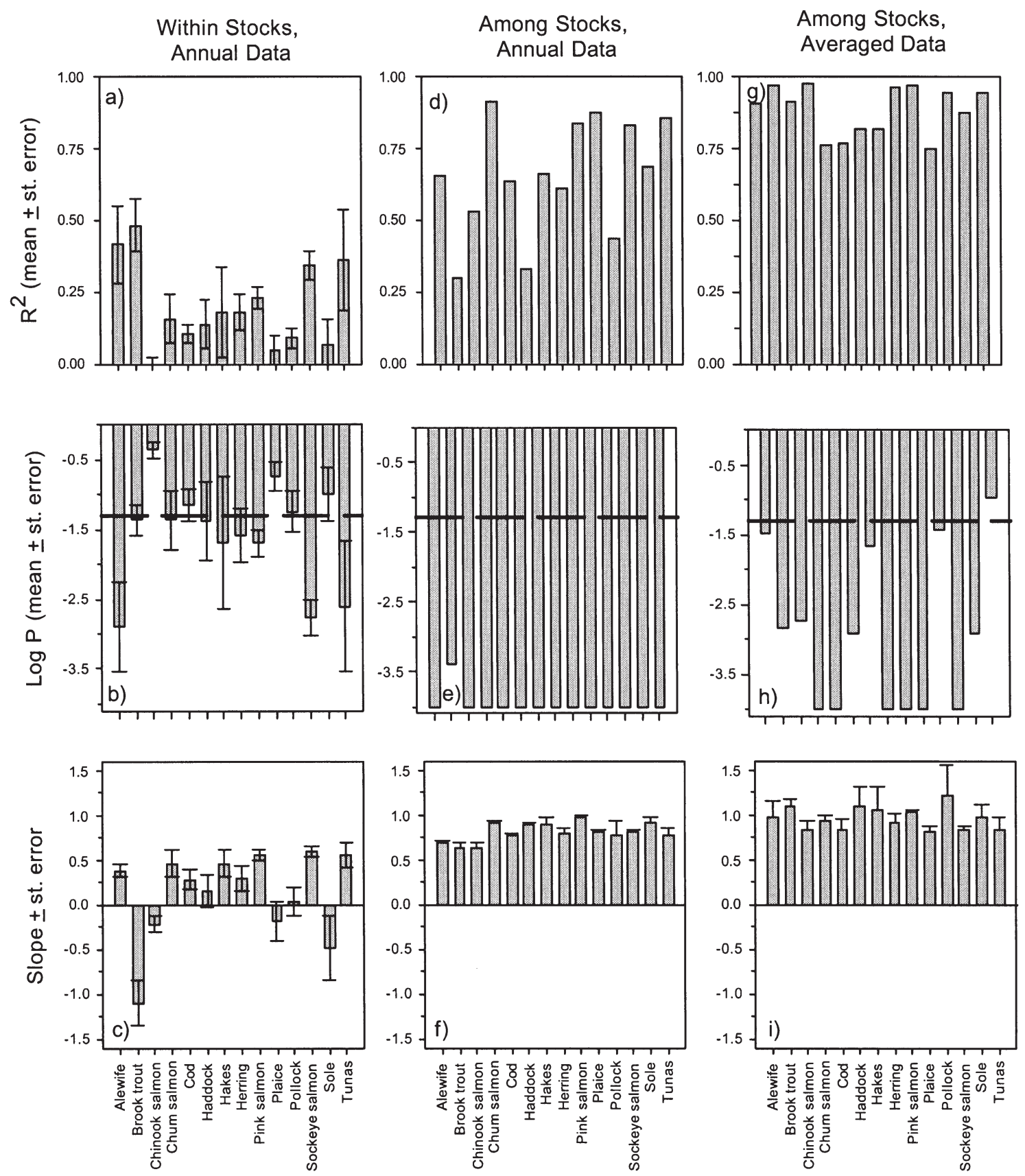

Fig. 2. Statistical results $\left(\mathrm{R}^{2}\right.$, statistical significance $\mathrm{p}$ of slope, and slope estimate) for regression of log recruitment vs. log spawner-biomass at different levels of aggregation: panels (a) to (c): within-stocks using annual data; panels (d) to (f): amongstocks using annual data; panels (g) to (i): among-stocks using stock-averaged data. Note that panels (a) to (c), (d) to (f) and (g) to (i) correspond to statistical results derived from analyses which are represented schematically in Fig. 1a, b and c, respectively. Dashed horizontal lines on panels $\mathrm{b}$, e and $\mathrm{h}$ represent statistical significance level of $\mathrm{p}=0.05$ 


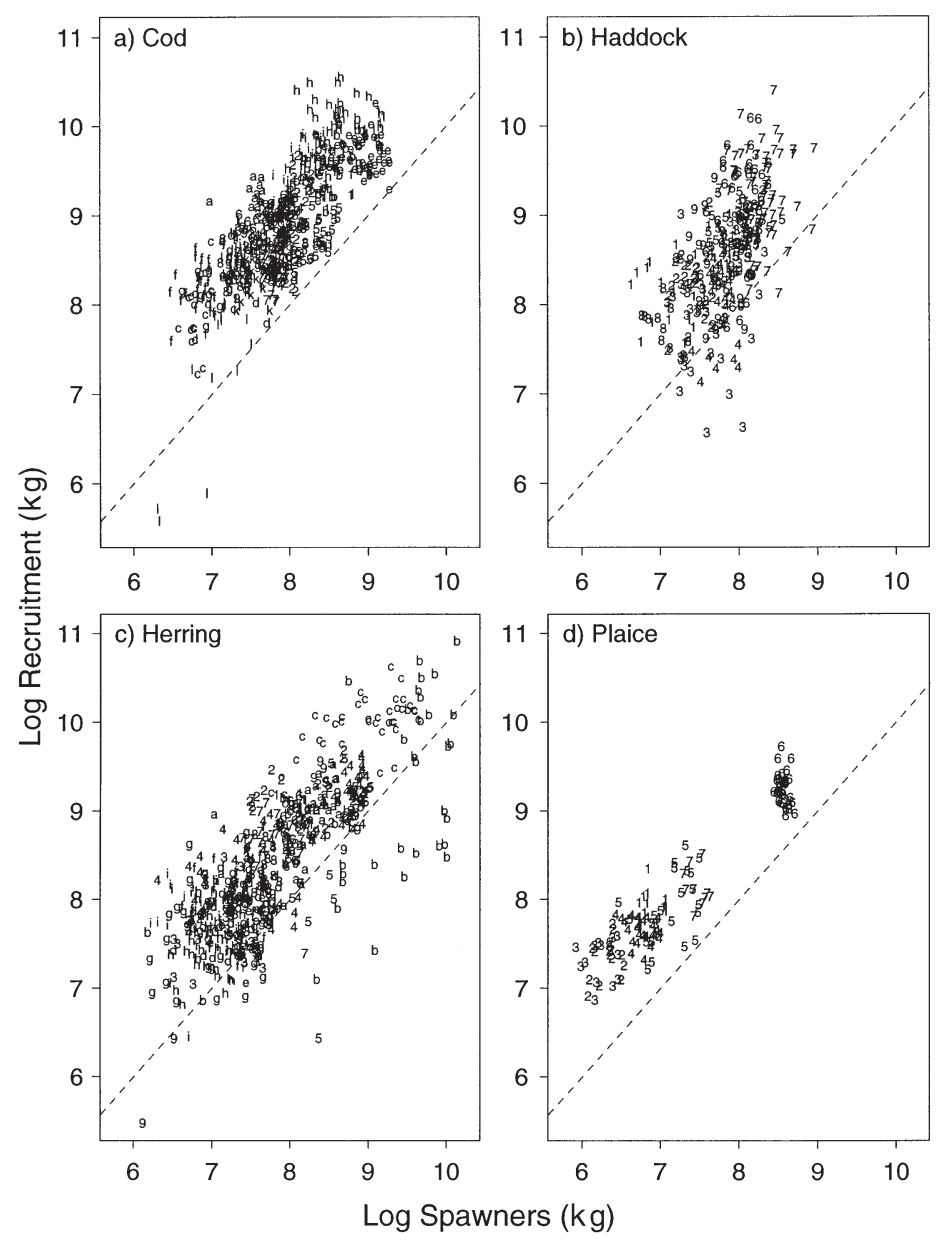

Fig. 3. Interannual variation in recruitment within stocks $\left(\log _{10}\right.$ recruitment $[\mathrm{kg}]$ and $\log _{10}$ spawner biomass [kg]) where each stock is identified by a number or letter code (see Table 1). Data are for (a) 20 cod Gadus morhua stocks, (b) 9 haddock Melanogrammus aeglefinus stocks, (c) 18 herring Clupea harengus stocks and (d) 7 plaice Pleuronectes platessa stocks. Each symbol represents 1 cohort for each stock. Note that both recruits and spawners are given in the same units. The dotted line is the replacement line, and the distance of each point above that line gives the increase of a cohort that would occur if no fishing occurred

cruitment was only weakly related to spawning biomass; the mean amount of variation in log recruitment explained by log spawner-biomass was usually $<25 \%$ for most stocks and species (Fig. 2a,b). Slopes of the fitted models were usually positive (range: -1.1 to 0.4 ; Fig. $2 \mathrm{c}$ ), although negative for brook trout, sole, chinook salmon and plaice. However, among this group of species only the brook-trout stocks had high correlations.

\section{Variability among stocks within a species}

The second level of recruitment variability we considered was among stocks within a species (Fig. 1b,c).
Strong relationships between recruitment and spawner biomass were evident. This pattern was obvious when comparing either interannual spawnerrecruitment data (Figs. 2d \& 3; see stock codes in Table 1) or stock-specific averages (Figs. $2 g$ \& 4). In the former case, log spawner-biomass usually explained $>50 \%$ of the variance $\left(\mathrm{R}^{2}\right)$ in interannual recruitment data, and relationships were always highly significant ( $\mathrm{p}=0.0004$ for brook trout and $\mathrm{p}<$ 0.0001 for other species; Fig. 2e). When the stockspecific interannual data are aggregated to stock means, mean log spawner-biomass always explains $>70 \%(\mathrm{p}<0.05)$ of the variation in mean log recruitment (Fig. 2g,h) and as a result residual variation from the fitted models was smaller (Fig. 5) than when using interannual data.

Interannual recruitment variability is higher for some species than others. For example, recruitment in some years for some haddock and herring stocks was below the 1:1 stock replacement line (Fig. 3b,c), whereas most of the observations for cod and plaice lie above the line (Fig. 3a,d). Spawner abundance
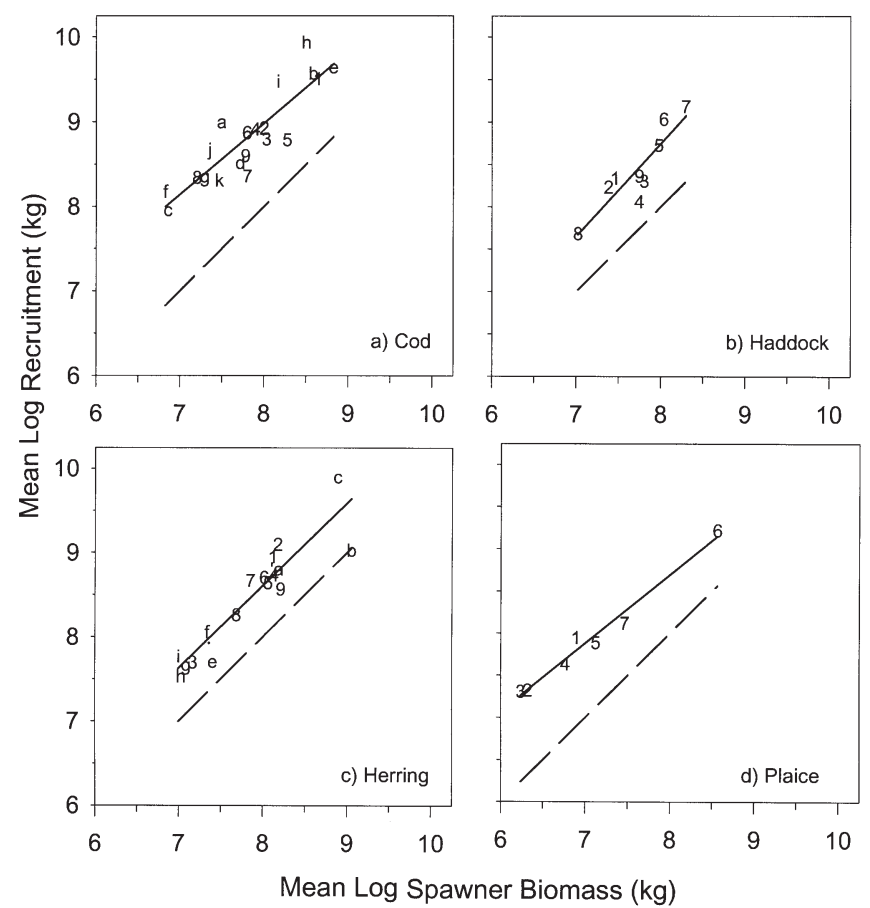

Fig. 4. Variability in recruitment among stocks within a species (mean $\log _{10}$ recruitment $[\mathrm{kg}]$ and mean $\log _{10}$ spawning stock biomass [kg]). Data are for (a) 20 cod Gadus morhua stocks, (b) 9 haddock Melanogrammus aeglefinus stocks, (c) 18 herring Clupea harengus stocks and (d) 7 plaice Pleuronectes platessa stocks. Symbols represent different stocks (see Table 1 for symbol definitions). Each symbol represents the mean for one stock and the solid line is the Type I linear regression model relating mean $\log _{10}$ recruitment to mean $\log _{10}$ spawning stock biomass. The dotted line is the $1: 1$ replacement line. See also Fig. 1 
Table 1. Stock codes corresponding to symbols in Figs. 1 \& 2

\begin{tabular}{|lllll|}
\hline & Cod & Haddock & Herring & Plaice \\
\hline 1 & NAFO 2J3KL & NAFO 4TVW & W. Baltic SD 22-24 & ICES VIId \\
2 & NAFO 3NO & NAFO 4X & NAFO 4-5 & ICES VIIe \\
3 & NAFO 3Pn4RS & NAFO 5Z & Central Coast BC & Celtic Sea \\
4 & NAFO 3Ps & Færoe Plateau & Downs stock & Kattegat \\
5 & NAFO 4TVn & Iceland & Georges Bank & North Sea \\
6 & NAFO 4VsW & NE Arctic & Gulf of Finland & Skagerrak \\
7 & NAFO 4X & North Sea & Gulf of Maine & Gulf of Riga \\
8 & NAFO 5Y & Rockall & Iceland (spring spawners) \\
9 & W. Scotland & Iceland (summer spawners) \\
$\mathrm{a}$ & W. Baltic SD 22-24 & & Norway (spring spawners) \\
$\mathrm{b}$ & E. Baltic SD 25-32 & & North Sea & No. Strait of Georgia \\
$\mathrm{c}$ & Celtic Sea & & NW Coast Vancouver Island \\
$\mathrm{d}$ & Færoe Plateau & & Prince Rupert District \\
$\mathrm{e}$ & Iceland & & Queen Charlotte Islands \\
$\mathrm{f}$ & Irish Sea & & Southern Strait of Georgia \\
$\mathrm{g}$ & Kattegat & & SW Coast Vancouver Island \\
$\mathrm{h}$ & NE Arctic & & \\
$\mathrm{i}$ & North Sea & & \\
$\mathrm{j}$ & Skagerrak & & \\
$\mathrm{k}$ & W. Scotland & & \\
\hline
\end{tabular}
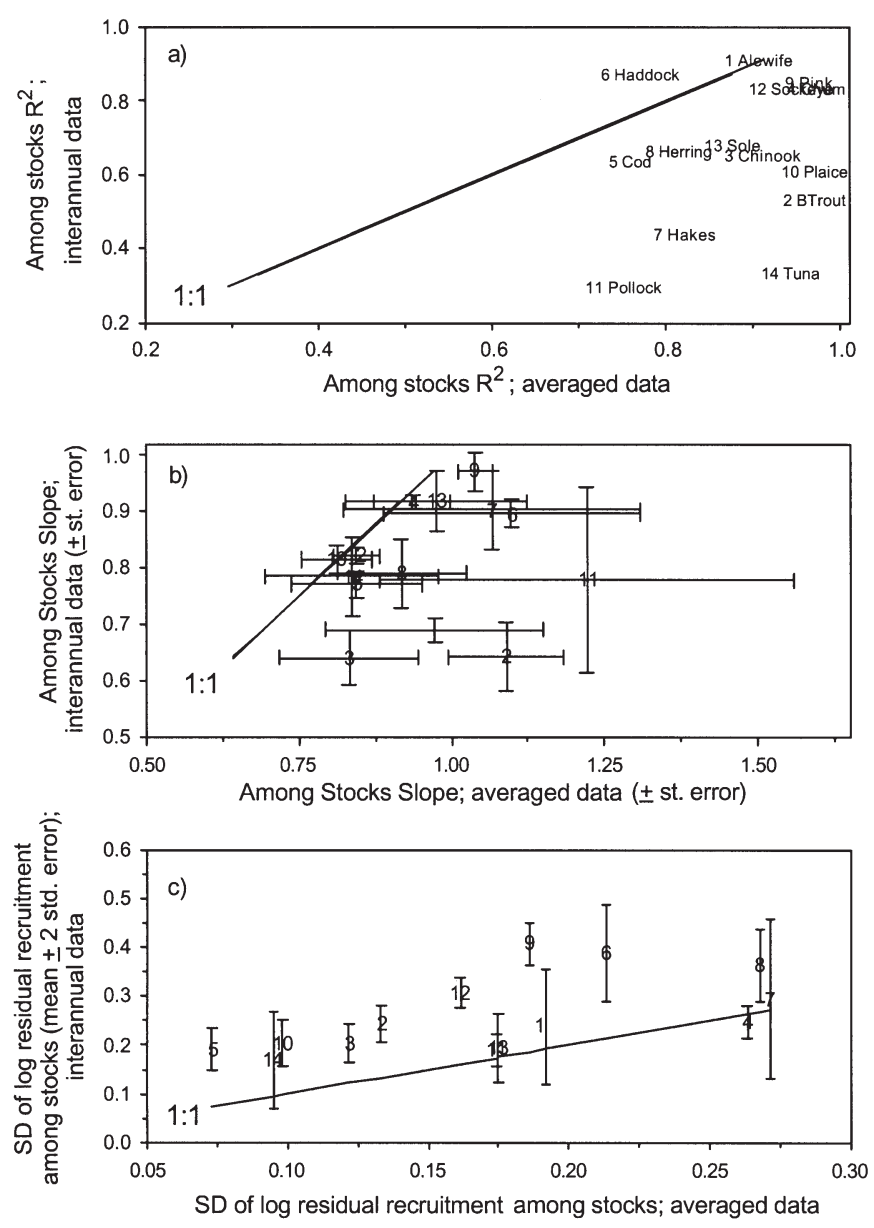

Fig. 5. Comparisons of model fits $\left(\mathrm{R}^{2}\right)$, slopes and residual variances for among stocks stock-recruitment relationships involving interannual or stock-averaged data. Symbol codes in (b) and (c) denote species as given in (a) generally explained more variation in recruitment for salmonid and flatfish species (higher $\mathrm{R}^{2}$ ) than for gadoid species (Fig. 2d,g).

The slopes of the relationships between log recruitment and log spawner-biomass among stocks were generally higher than those observed for the withinstocks analysis (cf. Fig. 2f,i with Fig. 2c; see also Fig. 5). Slopes from the among-stocks relationships were approximately 1 (log-log scale) for nearly all species, particularly when stock-specific mean spawner biomass and recruitment data were used in the analyses (Figs. 2i \& 5b); only plaice and sockeye salmon had slopes which differed significantly from 1 (Fig. 2i; $t$-test: $\mathrm{p}<0.05$ and $<0.001$, respectively).

We compared geographic variation in recruit production per spawner among stocks for 3 species (cod, haddock and herring). Some geographic regions occupied by a given stock seemed to produce more recruits per unit spawner biomass than others (Fig. 6). When the residuals from the mean log recruitment-mean log spawner-biomass relationships are back-transformed to arithmetic units, the range in residual recruitment relative to the mean is \pm 3 -fold among regions, and 8-fold between sites with the lowest and highest residual variation.

\section{Variability among species}

The third level of recruitment variation is that among species (Fig. 1d). Some species produced more recruits per spawner biomass than others (Fig. 7). That is, mean log recruit-mean log spawner regression relationships for some species were higher above the 1:1 replace- 

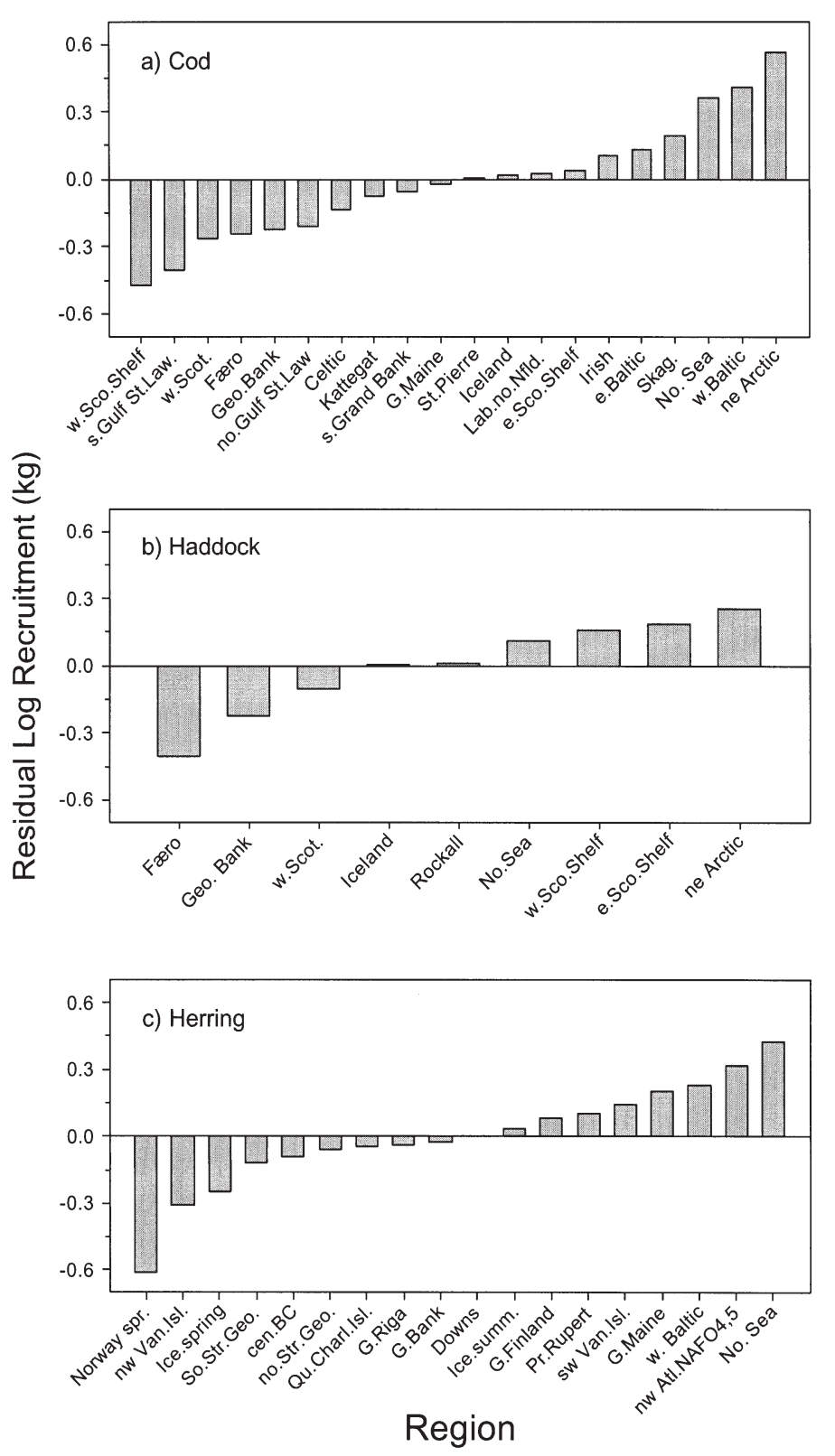

Fig. 6. Variability in recruitment among stocks within a species not explained by mean $\log _{10}$ spawner biomass. Residual variation shown is that obtained from regression analyses of mean $\log _{10}$ recruitment $(\mathrm{kg})$ vs. mean $\log _{10}$ spawning stock biomass (kg). Data are for (a) 20 cod Gadus morhua stocks, (b) 9 haddock Melanogrammus aeglefinus stocks, (c) 18 herring Clupea harengus stocks

ment line than others (Fig. 7). If the slope of this relationship is assumed equal to 1 (Fig. 2i), then the mean $\log$ recruit per $\log$ spawner-biomass $(\log \beta)$ for each of 14 species can be estimated (see 'Methods').

The estimate of $\beta$ ranged from 3 to 10, and salmonid species generally had low $\beta$ s while cod and plaice had higher values (Fig. 8a). There were large differences in
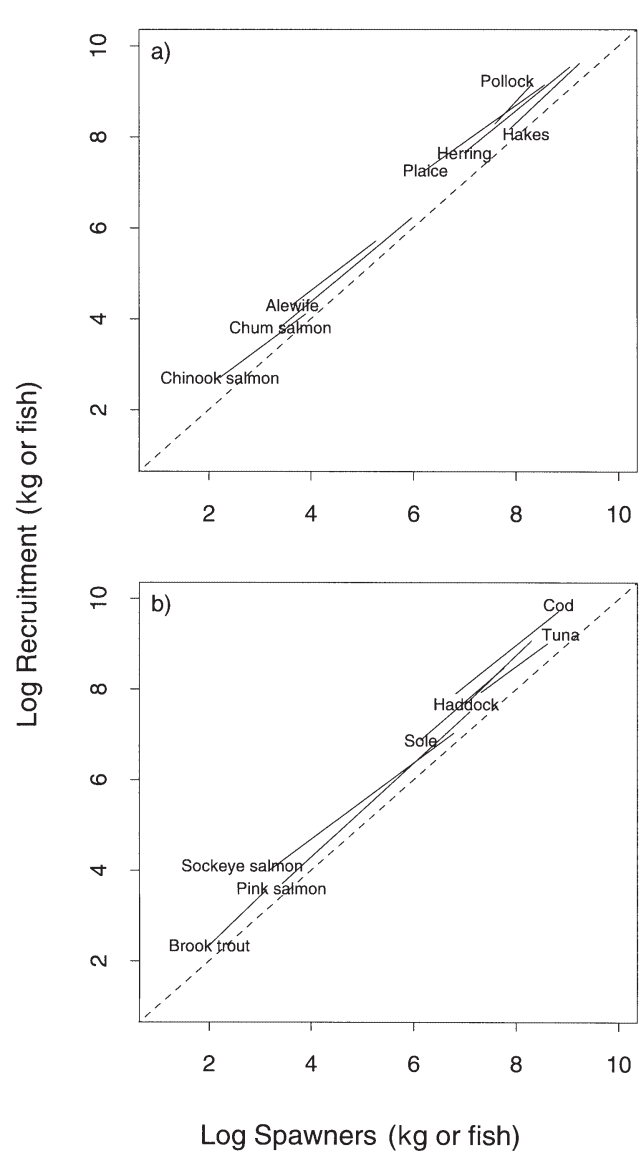

Fig. 7. Variability in stock-recruitment relationships among species (analogous to Panel d in Fig. 1). Fitted regression lines show the relationship between mean $\log _{10}$ recruitment $(\mathrm{kg})$ and mean $\log _{10}$ spawner biomass $(\mathrm{kg})$ for several marine, anadromous, and freshwater species. $\mathrm{R}^{2}$, statistical significance (p) and slope values are presented in Fig. 2 (g to i). The dotted line is the 1:1 replacement line. See 'Results; Variability among species' for further details

the variability (standard deviation) of $\beta$ among species (Fig. 8b); for example, the variability in mean log recruitment per mean log spawner-biomass among cod stocks (and the other gadoids) is greater than that for the flatfishes and salmonids. However these differences were generally not statistically significant because of low sample sizes for many of the species used in the analysis. For example, the 2 species with the largest and smallest variances did not differ significantly (variance ratio test: $F_{18,3 \text { df }}=10.96 ; F_{0.05(2)}=14.2$; Zar 1999).

\section{Abundance-area relationships}

The high correlation between log recruitment and log spawner-biomass among stocks within a species is at least partly due to combining stocks inhabit- 

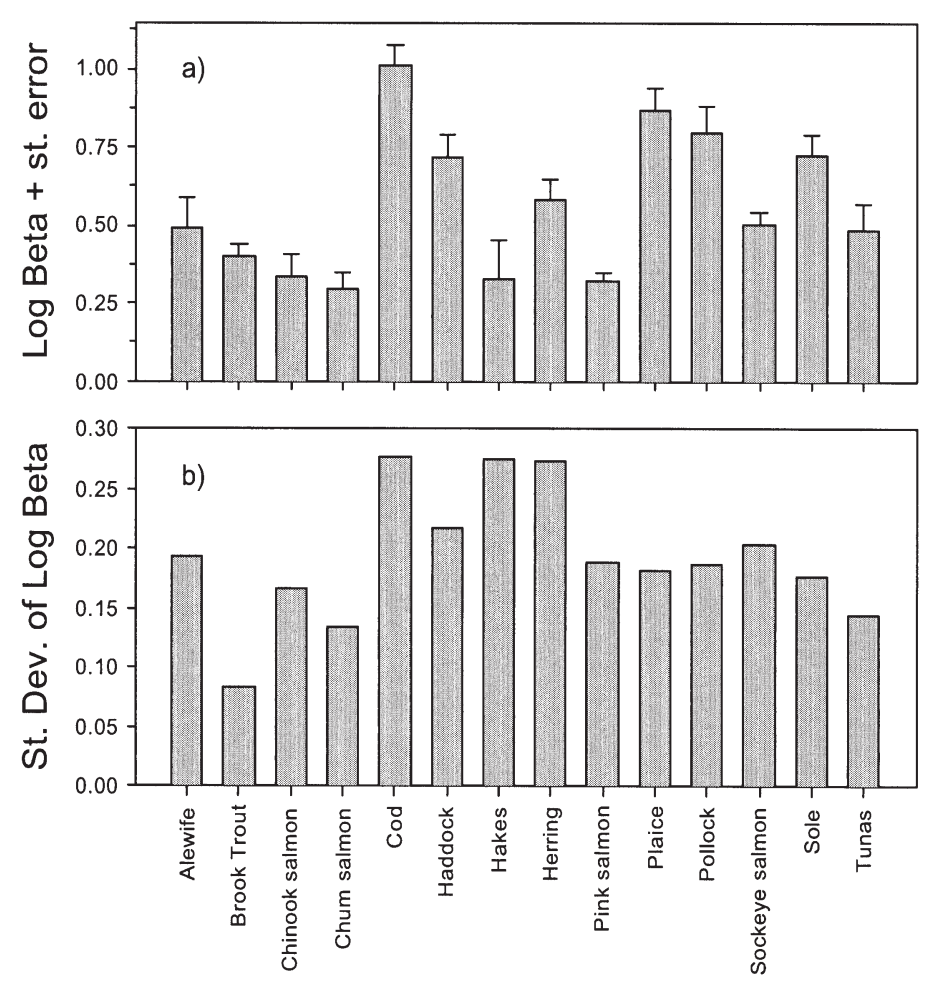

Fig. 8. Among-species variation in recruitment above replacement levels. (a) Mean difference $(\log \beta$; see 'Methods; Statistical analyses' for definition) and standard error between log recruitment $(\mathrm{kg})$ and log spawner biomass $(\mathrm{kg})$ across stocks within each species. (b) Standard deviation of $\log \beta$ across stocks within each species

ing regions of different sizes. Both recruitment and spawner biomass for one species (cod) were significantly correlated with habitat area (Fig. 9, Table 2). However, log area did not explain additional significant variation in mean log recruitment when included in a multiple regression analysis with mean $\log$ spawner-biomass (Table 2).

\section{DISCUSSION}

\section{General}

This paper raises issues which have been largely overlooked by fisheries population biologists. We have found that recruitment variability within species is clearly related to spawner biomass, and the nature of this relationship (e.g. its functional form, residual variability) is relatively similar among species. We have also observed that recruitment per spawner among stocks is variable throughout a species' range. This result suggests that carrying capacity for new recruit production differs between ecosystems.

\section{Spawner-recruit relationships}

In this section we consider 3 levels of recruitment variability: interannual variability within a stock, among stock variability within a species, and among species variability.

\section{Interannual variability within a stock}

For most stocks the spawner-recruitment relationship is typically dominated by large unexplained variability (Cushing 1995, Myers \& Barrowman 1996, Myers 2001). This pattern was also evident in our analyses. Much research effort is attempting to clarify and distinguish processes responsible for this variation (e.g. Campbell 1997, Coombs et al. 1998), although with limited success for most stocks (Myers 2001). In most cases in our analyses, the expected recruit production for all stocks and all years was above the 1:1 replacement line, indicating that the stocks are able to produce sufficent new recruits to prevent the stock from collapsing. However, stock collapses due to low recruitment per spawner biomass were evident in some cases.

As examples, the Norwegian spring-spawning herring (Code b in Fig. 3c and Table 1) and some haddock
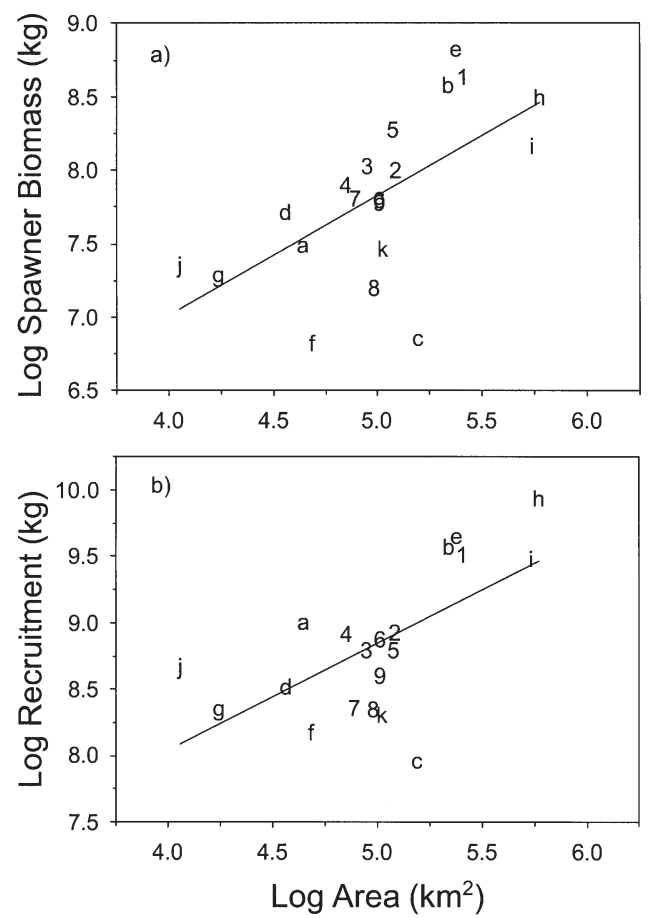

Fig. 9. Among stocks variation in mean (a) log spawnerbiomass and (b) mean log recruitment explained by log habitat area for 20 stocks of cod Gadus morhua. Symbol codes represent stocks and are listed in Table 1 
Table 2. Regression statistics for relationships between cod mean recruitment, mean spawner abundance and habitat area for 20 populations. All analyses used means of $\log _{10}$-transformed data; $R=$ recruits $(\mathrm{kg}), S=$ spawner biomass $(\mathrm{kg})$, $A=$ area $\left(\mathrm{km}^{2}\right)$. Regression coefficients are shown $\pm 1 \mathrm{SE}_{i} \mathrm{R}_{\text {adj }}^{2}=$ correlation coef$\mathrm{RMSE}=$ root mean square error from regression model

\begin{tabular}{|lccrc|}
\hline \multicolumn{1}{l}{ Model } & $\mathrm{R}^{2}$ adj & $\mathrm{p}_{\text {overall }}$ & $\mathrm{p}_{\text {coeff. }}$ & RMSE \\
\hline $\log R=0.80 \pm 0.23 \times \log A$ & 0.36 & 0.0029 & 0.0029 & 0.436 \\
$\quad+4.84 \pm 1.16$ & & & 0.0006 & \\
$\log S=0.82 \pm 0.24 \times \log A$ & 0.35 & 0.0034 & 0.0034 & 0.457 \\
$\quad+3.72 \pm 1.22$ & & & 0.0069 & \\
$\log R=0.84 \pm 0.11 \times \log S$ & 0.76 & $<0.0001$ & $<0.0001$ & 0.268 \\
$\quad+2.24 \pm 0.85$ & & & 0.0170 & \\
$\log R=0.76 \pm 0.14 \times \log S$ & 0.76 & $<0.0001$ & $<0.0001$ & 0.269 \\
$\quad+0.17 \pm 0.18 \times \log A$ & & & 0.3585 & \\
$\quad+2.01 \pm 0.88$ & & & 0.0365 & \\
\hline
\end{tabular}
ficient adjusted for the number of degrees of freedom, $\mathrm{p}=$ probability level,

cies-specific regression models), although $\sim 8$ fold, may seem relatively small to some readers given the wide range of possible environmental effects that can potentially affect recruitment within a stock. Log recruitment in stocks throughout a species range was close to the overall mean log recruitment (for a given log spawner-biomass) as represented by the fitted spawner-recruit regression relationship, despite large differences in environmental and biological conditions (e.g. temperatures, predation, etc.) that can exist between regions inhabited by different stocks.

The strong relationships between log spawnerbiomass and log recruitment among stocks indicates that

stocks (Codes 3, 4, 6, 7 and 9 in Fig. 3b and Table 1) have had several years of extremely low recruitment for the given spawning stock size. This pattern indicates that under some circumstances spawner biomass itself will not be sufficient for strong year-classes because other factors (e.g. environmental effects on egg production by spawners or on pre-recruit survival) negatively affect recruitment. If several years of poor environmental conditions occur in a relatively short period, particularly when combined with high fishing mortality, stock levels can quickly decrease (Watanabe et al. 1995, Wada \& Jacobson 1998, Jarre-Teichmann et al. 2000). Conversely, average or high recruitment per unit spawning stock may not be sufficient to prevent stock collapses when fishing mortality of juveniles and pre-recruits is high. For example, cod stocks in the NW Atlantic collapsed in the late 1980s to early 1990s due mainly to high fishing mortality, even though recruitment was apparently sufficient to replace spawning stock levels existing at that time (Myers et al. 1996, 1997).

Recruitment variability among stocks within a species

Variability in recruitment at scales other than withinstock (i. e. interannual) has received much less attention by fisheries biologists and fisheries oceanographers.

We have shown that relationships between log spawner-abundance and log recruitment among stocks are highly significant. The influence of log spawnerabundance on log recruitment at the large space-time scales (i.e. among stocks, and for time periods of 2 to 3 decades) considered in this study is apparently much more significant than local ecosystem effects on recruitment. Differences in recruit production per spawner among stocks (i.e. the residual variation from the spe- spawner biomass is the single most important factor that determines long-term mean recruitment levels. This factor is more important than regional environmental influences and various measurement errors. This result is similar to some previous species-level spawner-recruitment analyses (Garrod \& Knights 1979, Jakobsen 1996, Myers \& Barrowman 1996). The strength of the among-stocks spawner-recruit relationships is partly a consequence of abundancearea relationships. When considering the large spatial scales of entire species, differences in spawner biomass in regions of different size clearly have a much stronger impact on recruitment than other variables. Although most of our log spawner-log recruit relationships explained high amounts of recruitment variation, the relationships for some species (e.g. cod, haddock) were more variable than relationships for other species (e.g. flatfishes). The variation within the cod and haddock relationships suggests that some ecosystems occupied by stocks of these species may be more productive in terms of recruit production per spawner biomass unit than others (see 'Carrying capacity of different ecosystems and among-stocks recruitment variability' below).

\section{Recruitment variability among species}

Spawner-recruit relationships at the species level, as obtained using standardized data, are approximately similar in terms of slope $(\sim 1)$ and explained variation. This pattern is robust despite differences in life-history and habitat (marine, anadromous, freshwater). Differences in spawner-recruit slopes among species were relatively small, and some species (e.g. cod, herring) had more variable relationships than others (plaice, sole, salmonids), although the differences in variability 
were not statistically significant. These patterns are consistent with an earlier comparison of recruitment among species using different methods and datasets (Leggett \& Frank 1997).

In general, all species and stocks produced on average an excess of recruits to replace the spawners in the population. However, there were some important differences in recruit production per spawner among species (range 3 to 10). In particular, cod appears to be one of the most productive species, while salmonids appear to be the least productive species, although reasons for these differences are not clear and may be related to interactions between exploitation and densitydependent mortality. The high recruit-per-spawner potential of cod, especially when compared with other species, might partly explain why many cod stocks resisted collapse for many years despite high exploitation rates (Myers et al. 1996, 1997). These differences need further investigation.

\section{Carrying capacity of different ecosystems and among-stocks recruitment variability}

Differences in recruit production per unit spawner abundance exist among stocks of a species and therefore between ecosystems occupied by these stocks. In the case of cod, haddock and herring, some regions on average have produced ca. 8-fold more recruits than other regions over the last 2 to 4 decades. We have shown, using alternative, more rigorous methods (stock-specific Beverton-Holt spawner-recruit curves fitted to the same cod data using Bayesian methods and area-standardized data), that differences in carrying capacity for cod exist, and are large (ca. 10-fold; Myers et al. 2001). Both of our studies suggest that ecosystems differ in their ability to produce new recruits of a given species, even after allowing for differences in spawner biomass. In comparison, the regional variability in maximum reproductive rate of cod at low abundance is essentially constant among stocks (30 to 35 new spawners per fish; Myers et al. 1999). We interpret the differences in recruit production per spawner among stocks as differences in carrying capacity for recruit production and survival.

The ecological processes that generate differences in carrying capacity are not clear, particularly after the influence of spawner biomass is accommodated in the analysis. However, the processes might include differences in primary production rates, interactions with other species (e.g. competition, predation: Swain \& Sinclair 2000, Myers et al. 2001) and abiotic factors (e.g. temperature: Planque \& Frédou 1999, Brander 2000).

The results of our analyses apply to fishing/environmental conditions typical for the last 2 to 4 decades.
This is the time period covered by most of the spawner and recruit data in our analyses. Carrying capacities and stock dynamics under different time periods could be different because of changes in food webs (e.g. predators, competitors; Micheli 1999, Steele \& Schumacher 2000) and environmental variability. For example, environmental changes associated with carrying capacity are believed responsible for a 75-fold increase in recruitment per spawner biomass of Japanese sardine between 1951-70 and 1971-95 (Wada \& Jacobson 1998).

The dynamics of carrying capacity and stock productivity may be relevant for fisheries management. Stock rebuilding efforts following stock collapses could require far more (less) time, if conditions have switched to a lower- (higher-) capacity regime once the stock has been reduced, given that maximum reproductive rates within populations of a fish species are relatively constant (Myers et al. 1999). Such a switch in carrying capacity may have occurred both in Atlantic Canada, where recovery of cod stocks is taking longer than expected from single-species models of stock biology (Sinclair et al. 1997), and in the north Pacific, where climate-related regime shifts influence fish production (Hutchings 2000, Hollowed et al. 2001). Detecting such changes requires long time-series, which are becoming increasingly available.

\section{Habitat area relationships}

We have observed that cod biomass (both spawners and recruits) increases logarithmically with a simple definition of habitat size (mean slope and standard error $\sim 0.8$ and 0.2 , respectively).

The abundance-area patterns suggest that space (or factors associated with space) sets the overall limit to cod abundance within the different regions. Abundance-area relationships have also been reported for herring (Iles \& Sinclair 1982, Hay \& McCarter 1997) and sole (Rinjsdorp et al. 1992). For example, mean herring recruitment in the NW Atlantic was related to the size of larval nursery areas ('retention zones'; Iles \& Sinclair 1982), and maximum herring biomass for 14 populations was strongly correlated with summer feeding habitat area, which was assumed to be represented by continental shelf area (0 to $200 \mathrm{~m})$. The range of herring densities reported by Hay \& McCarter (1997) is 0.2 to $10 \mathrm{t} \mathrm{km}^{-2}$. In comparison we have shown elsewhere (Myers et al. 2001) that the maximum cod spawner biomass density (i.e. the asymptotes of fitted Beverton Holt models) in $20 \mathrm{cod}$ populations has approximately the same range (ca. 0.1 to $8 \mathrm{t} \mathrm{km}^{-2}$ ) as that observed for the herring populations. 
The abundance-area relationship that we identify for cod is an approximation because of our simple definition of habitat size. We assumed for cod that the limiting factors for recruit production were processes correlated with area of the sea bottom between 0 and $300 \mathrm{~m}$ depth, although the specific mechanisms that affect mortality during different life-history stages (egg, larval, juvenile, adult) are poorly known for cod stocks. For some stocks, density-dependent processes after settlement seem most important for recruitment (Myers \& Cadigan 1993, Heath \& Gallego 1998), whereas for other stocks, processes in the pelagic stage can be important (Brander 2000, Jarre-Teichmann et al. 2000, Swain \& Sinclair 2000). Our results suggest that the impact of these processes on survival of cod recruits is associated with habitat size.

The results with cod show that a given ecosystem has a carrying capacity which defines the approximate size of the cod population within that ecosystem. This result no doubt applies to other species (e.g. herring, sole) and implies strong density-dependence within each of the populations. Density-dependence was evident in our Fig. 2c and Cushing's (1971) analyses of the within-population stock-recruitment relationship, where slopes were always less than 1. Density dependence is also evident in a wide range of field studies of fish ecology (e.g. surveys of juvenile abundance, growth and cannibalism: Sparholt 1994, Myers 2001, Lekve et al. 2002).

In contrast, the among-stock relationships generally had slopes which approximated 1 . This result suggests that density dependence may not be important in controlling abundance; we note that slopes $\sim 1$ are usually only seen within stocks at low population sizes (Myers 2002), where density dependence is relatively low. However we believe that density dependence does control abundances in most of the stocks and species considered here, and that the high slopes of our among-stocks relationships are a consequence of conducting an analysis which combines stocks inhabiting different sizes of habitats. In this case, the differences in habitat size are so large that they support a wide range in abundances. As a result, the among-stock analyses show that recruitment depends strongly on spawner biomass. This is evident despite the fact that slopes $\sim 1$ are more typically seen at low population sizes within single populations (Myers 2002), and strong density-dependence can (and usually does) exist at the within-stock level.

\section{Conclusions}

Comparative analyses of spawner-recruit relationships have shown that most of the variation in log recruitment among stocks of a given fish species is explained by log spawner-biomass: populations with high spawner biomass tend to produce more recruits than populations with low spawner biomass. These analyses have also shown that mean log recruitment is directly proportional to mean log spawner-biomass (slope of the log spawner-log recruit relationship is approximately 1) and that the production of new fish per unit spawner biomass varies among stocks within a species and among species. We conclude that spawner biomass explains much more of the variability in recruitment among stocks than within stocks.

Acknowledgements. Partial funding was provided by DIFRES and a grant from the European Union (FAIR contract CT983959; coordinator Prof. Dr. D. Schnack, Institute of Marine Science, Kiel, Germany).

\section{LITERATURE CITED}

Bakun A (1996) Patterns in the ocean: ocean processes and marine population dynamics. BCS Mexico, California Sea Grant System, NOAA and Centro de Investigaciones Biologicas del Noroeste, La Paz, p 1-323

Brander K (2000) Effects of environmental variability on growth and recruitment in cod (Gadus morhua) using a comparative approach. Oceanol Acta 23:485-496

Campbell JS (1997) Introduction to the Northwest Atlantic cod symposium. Can J Fish Aquat Sci 54(Suppl 1):1

Coombs S, Harris R, Perry I, Alheit J (1998) Globec special issue: foreword. Fish Oceanogr 7:175

Cushing DH (1971) The dependence of recruitment on parent stock in different groups of fishes. J Cons Int Explor Mer 33(3):340-362

Cushing DH (1995) Population production and regulation in the sea: a fisheries perspective. Cambridge University Press, Cambridge, p 1-354

Fuller WA (1987) Measurement error models. John Wiley \& Sons, New York

Garrod DJ, Knights BJ (1979) Fish stocks: their life-history characteristics and response to exploitation. Symp Zool Soc Lond 44:361-382

Hay DE, McCarter PB (1997) Continental shelf area and distribution, abundance and habitat of herring in the North Pacific: forage fishes in marine ecosystems. In: Mecklenburg CW (ed) Proc Int Symp Role of Forage Fishes in Marine Ecosystems. Alaska Sea Grant Colleage Program Report No. 97-01. University of Alaska, Fairbanks, p 559-572

Heath MR, Gallego A (1998) Bio-physical modelling of the early life stages of haddock in the North Sea. Fish Oceanogr 7:110-125

Hennemuth RC, Palmer JE, Brown BE (1980) A statistical description of recruitment in eighteen selected fish stocks. J Northw Atlant Fish Sci 1:101-111

Hilborn R, Walters C (1992) Quantitative fisheries stock assessment: choice, dynamics and uncertainty. Chapman \& Hall, New York

Hollowed AB, Hare SE, Wooster WS (2001) Pacific Basin climate variability and patterns of North Pacific marine fish production. Prog Oceanogr 49:275-282

Hutchings JA (2000) Collapse and recovery of marine fishes. Nature 406:882-885 
Iles TC, Beverton RJH (1998) Stock, recruitment and moderating processes in flatfish. J Sea Res 39:41-55

Iles TD, Sinclair M (1982) Atlantic herring: stock discreteness and abundance. Science 215:627-633

Jakobsen T (1996) The relationship between spawning stock and recruitment for Atlantic cod stocks. ICES CM 1996/ G:15

Jarre-Teichmann A, Wieland K, MacKenzie BR, Hinrichsen HH, Plikshs M, Aro E (2000) Stock-recruitment relationships for cod (Gadus morhua callarias L.) in the central Baltic Sea incorporating environmental variability. Arch Fish Mar Res 48:97-123

Kehler DG, Myers RA, Field CA (2002) Measurement error and bias in the maximum reproductive rate for the Ricker model. Can J Fish Aquat Sci 59:854-864

Leggett WC, Frank KT (1997) A comparative analysis of recruitment variability in North Atlantic flatfishes - testing the species range hypothesis. J Sea Res 37:281-299

Lekve K, Ottersen G, Stenseth NC, Gjøsæter J (2002) Length dynamics in juvenile coastal Skagerrak cod: effects of biotic and abiotic processes. Ecology 83:1676-1688

Marshall CT, Kjesbu OS, Yaragina A, Solemdal P, Ulltang $\varnothing$ (1998) Is spawner biomass a sensitive measure of the productive and recruitment potential of the north-east Arctic cod? Can J Fish Aquat Sci 55:1766-1783

Micheli F (1999) Eutrophication, fisheries, and consumerresource dynamics in marine pelagic ecosystems. Science 285:1396-1398

Myers RA (2001) Stock and recruitment: generalizations about maximum reproductive rate, density dependence, and variability using meta-analytic approaches. ICES J Mar Sci 58:937-951

Myers RA (2002) Recruitment: understanding density-dependence in fish populations. In: Hart PJB, Reynolds JD (eds) Handbook of fish biology and fisheries, Vol 1. Fish biology. Blackwell Science, Oxford, p 123-148

Myers RA, Barrowman NJ (1996) Is fish recruitment related to spawner abundance? Fish Bull 94:707-724

Myers RA, Cadigan NG (1993) Density-dependent juvenile mortality in marine demersal fish. Can J Fish Aquat Sci 50(8):1576-1590

Myers RA, Mertz G (1998) Reducing uncertainty in the bio-

Editorial responsibility: Otto Kinne (Editor),

Oldendorf/Luhe, Germany logical basis of fisheries management by meta-analysis of data from many populations: a synthesis. Fish Res 37: 51-60

Myers RA, Hutchings JA, Barrowman NJ (1996) Hypotheses for the decline of cod in the North Atlantic. Mar Ecol Prog Ser 138:293-308

Myers RA, Hutchings JA, Barrowman NJ (1997) Why do fish stocks collapse? The example of cod in Atlantic Canada. Ecol Appl 7(1):91-106

Myers RA, Bowen KG, Barrowman NJ (1999) Maximum reproductive rate of fish at low population sizes. Can J Fish Aquat Sci 56:2404-2419

Myers RA, MacKenzie BR, Bowen KG, Barrowman NJ (2001) What is the carrying capacity of fish in the ocean? A metaanalysis of population dynamics data from the North Atlantic. Can J Fish Aquat Sci 58:1464-1476

Planque B, Frédou T (1999) Temperature and the recruitment of Atlantic cod (Gadus morhua). Can J Fish Aquat Sci 56: 2069-2077

Rijnsdorp AD, van Beek FA, Flatman S, Millner RM, Riley JD, Giret M, de Clerck R (1992) Recruitment of sole stocks, Solea solea (L.), in the northeast Atlantic. Neth J Sea Res 29:173-192

Sinclair M, O'Boyle R, Burke DL, Peacock G (1997) Why do some fisheries survive and others collapse? In: Hancock DA, Smith DC, Grant A, Beumer JP (eds) Developing and sustaining world fisheries resources: the state of science and management. 2nd World Fisheries Congress. CSIRO Publishing, Collingwood, p 23-35

Sparholt H (1994) Fish species interactions in the Baltic Sea. Dana 10:131-162

Steele JH, Schumacher M (2000) Ecosystem structure before fishing. Fish Res 44:201-205

Swain DP, Sinclair AF (2000) Pelagic fishes and the cod recruitment dilemma in the northwest Atlantic. Can J Fish Aquat Sci 57:1321-1325

Wada T, Jacobson LD (1998) Regimes and stock-recruitment relationships in Japanese sardine (Sardinops melanostictus), 1951-1995. Can J Fish Aquat Sci 55:2455-2463

Watanabe Y, Zenitani H, Kimura R (1995) Population decline of the Japanese sardine Sardinops melanostictus owing to recruitment failures. Can J Fish Aquat Sci 52:1609-1616

Submitted: December 20, 2001; Accepted: November 1, 2002 Proofs received from author(s): February 7, 2003 